\title{
DEMANDAS JUDICIAIS EM SAÚDE DE PESSOAS COM DOENÇA ONCO- HEMATOLÓGICAS: JUDICIALIZAÇÃO DA SAÚDE EM QUESTÃO
}

\author{
Zilda Cristina dos Santos ${ }^{1}$. Agnaldo de Sousa Barbosa ${ }^{2}$ \\ ${ }^{1}$ Doutora. UFTM. Uberaba- Mg. \\ ${ }^{2}$ Doutor. UNESP. Franca- SP
}

DOI: 10.47094/IICNNESP.2021/106

\begin{abstract}
RESUMO
Trata-se de uma pesquisa de doutorado intitulada Demandas Judiciais em Saúde de pessoas com doenças onco-hematológica: estudo de caso acerca da efetividade social da judicialização em um Hospital Universitário. O objetivo geral de compreender o processo da efetivação do direito à saúde de pessoas com doenças onco-hematológicas de um hospital de ensino federal por meio do encaminhamento de demandas judiciais, no período de 2016 a 2018. Os métodos de investigação foram revisão de literatura, pesquisa de campo e documental, entrevista semiestruturada. Pautou-se também na experiência profissional da pesquisadora. A pesquisa evidenciou que a justiça contribui para efetivação do direito à saúde, quando não pensando apenas em cifras, mas na pessoa, na vida, na família a que estão vinculados os processos de judicialização; apontou desafios a serem superados como a ausência de inserção da temática na agenda política e a observação da judicialização como meio para aperfeiçoar a política de saúde.
\end{abstract}

PALAVRAS CHAVES: Serviço Social. Acesso à saúde. Judicialização.

ÁREA TEMÁTICA: Outros.

\section{INTRODUÇÃO}

A judicialização, na política de saúde, tem destaque quando se trata do Brasil. De 2015 para cá, presencia-se o aumento expressivo da judicialização na saúde, conforme discutido na Pierro (2017), “Apenas em 2015, o governo paulista gastou R\$ 1,2 bilhão em remédios e insumos para 57 mil pacientes que recorreram aos tribunais" justificada pelas lacunas deixadas pelo Sistema Único de Saúde, como também pelo não acesso às tecnologias da saúde, e também ao que o SUS utiliza como protocolo de atenção a certas doenças.

As demandas judicializadas na saúde vão, desde coisas simples, como acesso a consultas, exames, vacinas, vagas em leitos hospitalares, até às mais complexas, como exemplo, a alta tecnologia e medicamentos de alto custo para doenças raras e doenças oncológicas (objeto deste estudo). Nessa perspectiva, na análise do acesso integral à saúde, temos o princípio fundamental da vida e à saúde. Em contrapartida, temos os princípios orçamentários e a reserva do possível, sob análise constitucional, a ser normatizado para seu cumprimento. 
No caso da judicialização da saúde, com ênfase em ações voltadas para o tratamento oncológico (medicações e exames de alto custo), existem ações de vários solicitantes com o mesmo diagnósticos, mas com o resultado do processo judicial diferente. Para uns, resulta-se a sobrevida, para outros o óbito, mostrando a ausência de padronização e/ou a não utilização de outras experiências, refletindo na maneira de julgar, bem como no resultado.

\section{METODOLOGIA}

A pesquisa ocorreu no período de 2016 a 2018, aprovada pelo Comitê de Ética Pesquisa da Universidade Estadual Paulista “Júlio Mesquita Filho” sob CAAE- 73003317.7.0000.5408. Trata-se de um estudo de caso em que foram empregado o método qualitativo com o objetivo de compreender o processo pela efetivação do direito à saúde, por meio da judicialização de medicamentos, de pessoas com doenças onco-hematológicas de um hospital federal de ensino superior do estado de Minas Gerais, no período de 2016 a 2018.

Com a finalidade de se atingirem os objetivos propostos, desenvolveram-se as seguintes fases: a primeira fase foi a realização de uma revisão bibliográfica sobre o tema com o intuito de proporcionar a atualização e ampliação dos aportes teóricos da pesquisa a partir dos seguintes descritores: judicialização da saúde por medicamentos; acesso a serviços oncológicos no SUS; doenças onco-hematológicas; política nacional de atenção oncológica.

$\mathrm{Na}$ segunda fase foram aplicadas entrevistas semiestruturadas entre os atores que acompanharam e/ou acompanham os usuários em seu tratamento de saúde e demandas judiciais. Para realização das entrevistas foi feito contato com cada um dos possíveis participantes, apresentado a mesma e realizado o agendamento do para realização da pesquisa; contudo, neste momento todos os profissionais participantes da pesquisas solicitaram que fosse feito em formato online. A partir desta solicitação foi construído a entrevista e o Termo de Consentimento, Livre e Esclarecimento por meio da ferramenta Google Formulários. Após isso, foi encaminhado e-mail do link do formulário bem como a informação aos participantes, do período para responder que foi janeiro de 2018 a julho de 2018, após o envio do e-mail foram feitos novos contatos com a confirmação do recebimento bem como colocando à disposição para possíveis dúvidas.

No que diz respeito a entrevistas com usuários foram feitos um pré- testes que mostrou a necessidade da construção de um formulário mais simples e objetivo. Os usuários preferiram a participação presencial e direta, devido a limitação de acesso ferramentas de tecnologias. Dessa forma a entrevista foi agendada para ser realizadas no mesmo dia de consulta, respeitando a disponibilidade e condições dos usuários em participar. As entrevistas com usuários aconteceu durante todo o mês de agosto de 2018 .

Para aplicação das entrevistas, foi realizada a apresentação e a explicação do Termo de Consentimento Livre e Esclarecido (TCLE) aos sujeitos envolvidos. Participaram da pesquisa 8 usuários de núcleo de 24 usuários que tiveram demandas judiciais no período de 2016 a 2018, o que 
representou participação de 33, 3\% dos usuários. No que diz respeito a equipe médica participaram 8 de núcleo de 12 médicos da equipe de Onco-Hematologia, perfazendo $67 \%$ de participação, já o(a) assistente social participaram 1 de um núcleo de 3 profissionais que atuaram com demandas de judicialização, o que representou 33,3\% e no que diz respeito ao advogados participaram apenas 1 de núcleo de 2 profissionais representou $50 \%$.

Os critérios para participação da amostra compreendem: (1) usuário com doença oncohematológica ou seus familiares que tenham ajuizado ação por medicamento junto ao MPF; (2) ser usuário cadastrado nos serviços do setor de oncologia do hospital; (3) aceitar a participação voluntariamente da pesquisa. Constituem-se como critérios para a exclusão da amostra: (1) usuários já falecidos ou (2) que não aceitem participar voluntariamente da pesquisa. Para aplicação das entrevistas, foi realizada a apresentação e a explicação do TCLE aos referidos sujeitos. Participaram da pesquisa oito usuários, oito médicos, um assistente social e um advogado.

A pesquisa respeitou os princípios elencados na Resolução $n^{\circ} 510 / 16$, resguardando a integridade do sujeito da pesquisa, desenvolvendo-se dentro dos padrões éticos. Deve assim trabalhar para contribuir para o fortalecimento do trabalho multiprofissional na saúde, ampliar o acesso a informações e serviços para produção de conhecimento do tema abordado e para dar visibilidade ao trabalho do assistente social em equipe multiprofissional.

\section{RESULTADOS E DISCUSSÕES}

Considerando isso, essa pesquisa envolveu a participação dos atores do processo de judicialização, com ênfase nas pessoas com doenças onco-hematológicas, um público negligenciado pelo SUS, em face das peculiaridades desses pacientes diante de outros com outros tipos de câncer. Dessa forma, buscaram-se entrevistar médicos, assistentes sociais e usuários desse processo, sendo que para os usuários foram utilizado o pseudonome de flores sendo Hortênsias, Lírios, Violeta, Girassol, Azaleia, Begônia, Amarílis e Calêndula. Os profissionais médicos, assistente social e advogado receberam o pseudonome de sentimentos sendo: Compaixão, Sinceridade, Esperança, Gentileza, Gratidão, Angústia, Fé, Perseverança, Resiliência e Resignação.

A partir da análise e interpretação das entrevistas foi possível construir as seguintes categorias de análises: a) percepção dos usuários a respeito da judicialização; b) a contribuição do assistente social para o processo da judicialização; c) a visão do profissional do direito a respeito da judicialização da saúde; d) a visão da judicialização dos médicos prescritores. A construção destas categorias permitiram responder aos objetivos desta pesquisa, sendo possível compreender que a justiça contribui para efetivação do direito à saúde, em especial das pessoas com doença oncohematológicas. Contudo, existem muitos desafios a serem superados. Reconhece-se que este processo precisa de mais diálogo entre o Hospital Ensino Federal e Ministério Público, bem como efetivação dos acordos e ajustes propostos. 
Vale destacar aqui que, ao analisar o número de processos nos anos de 2016, 2017, 2018, encontramos os seguintes números: no de 2016 foi dado entrada em 11 processos, no ano de 2017 foram 4 processos e no ano de 2018 foram 9 processos, totalizando neste período 24 processos. No período desta pesquisa houve 9 óbitos deste grupo pessoas que judicializaram seus medicamentos, 5 não tiveram condições de participar da pesquisa, 2 não quiseram participar da pesquisa. Diante disso conseguiram-se oito participantes, de uma expectativa com aproximadamente 24 pacientes, representando 33,3\% do usuários que tiveram demandas judicializadas no período de 2016 a 2018.

Os diagnósticos que tiveram medicamentos judicializados foram: mieloma múltiplo e linfoma. Desses, apenas 33,3\% foram deferidos em tempo hábil para o usuário fazer uso das medicamentações, houve $67,7 \%$ de indeferimento dos processos. Desse núcleo de 24 participantes 37,5\%, faleceram com o processo ainda em andamento e/ou não tiveram condições de utilizar o medicamento devido à morosidade e ao avançado da doença.

No que diz respeito a categoria de análise da percepção do usuário sobre o processo de judicialização, verificou-se que as demandas se assemelham pois são utilizados os mesmo critérios para encaminhamento para a judicialização (esgotamento dos recursos/tratamento da saúde pública, comprovação cientifica, contribuições para o paciente). O que condiz com estudos de Carvalho e Leite (2014) que judicialização ocorre devido ao desabastecimento ou inexistência de protocolo clínico e terapêutico pelo SUS, este mesmo estudo, assim como descrito nesta pesquisa os usuários ao judicializarem se sentem inseguros. No que diz respeito categoria de análise a contribuição do assistente social para o processo da judicialização verificou-se a importância deste profissional no acompanhamento do itinerário da judicialização. No que diz respeito a categoria de análise a visão do profissional do direito a respeito da judicialização da saúde a pesquisa ilustra a visão positiva da judicialização da sua contribuição para efetivação do direito à saúde, contudo também apresenta algumas limitações. E na categoria a visão da judicialização dos médicos prescritores conflui para esse profissional a maior responsabilidade da ação. Frustam com os indeferimentos. Compreendem os determinantes e condicionantes sociais que interferem no processo de saúde, doença e cuidado. Preocupam-se com vida, qualidade de vida, prezam pela ética.Reconhecem as fragilidades e a importância social do SUS.

Apontam o distanciamento do judiciário da realidade do SUS.

\section{CONSIDERAÇÕES FINAIS}

Trazer essa experiência à tona é contribuir para que as pessoas acreditem no SUS e o defendam. É preciso também superar os interesses mercadológicos, ora vinculados à ideia de judicialização. Como apontado por essa pesquisa, alguns serviços de saúde não acolhem e/ou direcionam os usuários na busca da justiça para efetivação dos seus direitos, diferente do que acontece no cenário pesquisado, onde os profissionais de saúde acolhem e acompanham todo o processo de judicialização, mesmo após a disponibilização da medicação, ou seja, os usuários desse serviço sabem o itinerário para buscar a efetivação de seus direitos. Busca-se principalmente fazer com que essa área da oncologia 
seja representada nas discussões acadêmicas e científicas, pois além dos números e desafios aqui apontados, essa pesquisa se pautou na defesa da vida e da dignidade, na luta para efetivação de um direito, do papel do Estado, apesar de toda a conjuntura e estrutura social, política e econômica mostrarem o contrário, o que representa ainda desafios para a defesa do SUS, dos seus profissionais e usuários

\section{PRINCIPAIS REFERÊNCIAS}

CARVALHO, M. N.; LEITE, S. N. Itinerário dos usuários de medicamentos via judicial no estado do Amazonas. Interface - comunicação, saúde e educação, Botucatu, v. 18, n. 51, p. 737-748, 2014. Disponível em: < Disponível em: https://doi.org/10.1590/1807-57622013.0930> Acesso em: 03 mar. 2020.

PIERRO, B. Demandas crescentes. Revista Pesquisa FAPESP, São Paulo, n. 252, p. 18-25, fev. 2017. Disponível em: <http://revistapesquisa.fapesp.br/wp-content/uploads/2017/02/018-025_ Judicializacao_252_NOVO.pdf>. Acesso em: 04 abr. 2017. 